Supporting Information

\title{
Two-Dimensional Organic-Inorganic Hybrid Rare-Earth Double Perovskite Ferroelectrics
}

Chao Shi, Le Ye, Zhi-Xin Gong, Jia-Jun Ma, Qin-Wen Wang, Jia-Ying Jiang, Miao-Miao Hua, Chang-Feng Wang, Hui Yu, Yi Zhang*, Heng-Yun Ye*

Chaotic Matter Science Research Center, Department of Materials, Metallurgy and Chemistry, Jiangxi University of Science and Technology, Ganzhou 341000, P. R. China

*E-mail: yizhang1980@seu.edu.cn; hyye@seu.edu.cn

Crystal structure determination. Powder X-ray diffraction (PXRD) data were obtained on a Rigaku D/MAX 2000 PC X-ray diffractometer. Single-crystal diffraction data were collected on a Rigaku synergy diffractometer using Mo- $K_{\alpha}(\lambda=0.71073 \AA)$ radiation from a graphite monochromator. The crystal structures were resolved by the direct method and then refined by full-matrix least-square method based on $F^{2}$ using the SHELXTL program (G.M. Sheldrick, Crystal structure refinement with SHELXL, Acta Cryst., 2015, C71, 3-8). Non-hydrogen atoms were refined and located in difference Fourier maps. The positions of hydrogen atoms were generated geometrically with $U_{\text {iso }}=1.2 U_{\text {eq }}(\mathrm{C}$ and $\mathrm{N}$ ) or $1.5 U_{\text {eq }}(\mathrm{O})$. The high-temperature structures contain totally disordered organic cations. They were not modelled as the chemical senses. In some cases, the atoms were refined isotropically. These usually led to the relatively high $R 1$ values. For $(\mathrm{R} 3 \mathrm{HQ})_{4} \mathrm{RbCe}\left(\mathrm{NO}_{3}\right)_{8},(\mathrm{R} 3 \mathrm{HQ})_{4} \mathrm{RbEu}\left(\mathrm{NO}_{3}\right)_{8}$ and $(\mathrm{R} 3 \mathrm{HQ})_{4} \mathrm{RbSm}\left(\mathrm{NO}_{3}\right)_{8}$, the high-temperature paraelectric phase shows the pseudo tetragonal symmetry. The refinement with the orthorhombic space group $B 222$ as that for (R3HQ) ${ }_{4} \mathrm{KCe}\left(\mathrm{NO}_{3}\right)_{8}$ leads to some atoms' 'non positive definite' (NPD) and large electronic density residue, while refinement with the tetragonal space group I422 gives the relatively satisfactory model. This model can just reveal the disordered state of the nitrate ions and the organic cations. It does not reveal the real symmetry of the paraelectric phase. Since they are isostructural to the $(\mathrm{R} 3 \mathrm{HQ})_{4} \mathrm{KCe}\left(\mathrm{NO}_{3}\right)_{8}$, and have similar phase transition behaves, the real symmetry should be the same as that for $(\mathrm{R} 3 \mathrm{HQ})_{4} \mathrm{KCe}\left(\mathrm{NO}_{3}\right)_{8}$ (space group: B222). 
Measurements. Differential scanning calorimetry (DSC) measurements were carried out on a netzsch differential scanning calorimeter (polyma) under nitrogen at atmospheric pressure, with a heating/cooling rate of $10 \mathrm{~K} / \mathrm{min}$. TGA was measured with netzsch TG209F3. For dielectric measurements, single-crystal plates with well-defined directions were used (thickness, $\sim 0.3-0.50 \mathrm{~mm}$, area, $\sim 3-10 \mathrm{~mm}^{2}$ ). The directions of the crystals were determined on a Rigaku diffractometer (synergy). Silver conducting paste deposited on the plate surfaces was used as electrodes. A Tonghui TH2828A impedance analyzer was used to measure the dielectric constants. Pyroelectric property was measured with an electrometer/high resistance meter (keithley 6517B) with the heating rate of $10 \mathrm{~K} / \mathrm{min} . P-E$ hysteresis loops were calculated from current density-electric field (J-V) curves using the doublewave method [Nat. Commun. 2014, 5, 3279; J. Phys. Soc. Jpn. 2008, 77, 064706]. For second harmonic generation (SHG) measurements, an unexpanded laser beam with low divergence (pulsed Nd:YAG at a wavelength of $1064 \mathrm{~nm}, 5 \mathrm{~ns}$ pulse duration, 1.6 MW peak power, $10 \mathrm{~Hz}$ repetition rate) was applied. The system is based on the theory of KURTZ about the SHG of crystalline powders. The size of measured samples is about 200 mesh. Photoluminescence data of the solid samples were recorded on an Edinburgh EI-980 fluorescence spectrometer. Emission/excitation spectra were measured using the same slit and iris on a FLS980 fluorescence spectrometer (Edinburgh Instrument) equipped with a 450 W continuous wavelength Xe lamp, using Hamamatsu R928P (visible)photomultipliers.

Nanoscale polarization imaging and local switching spectroscopy were carried out using a resonant-enhanced piezoresponse force microscopy (MFP-3D, Asylum Research). Conductive Pt/Ircoated silicon probes (EFM-50, Nanoworld) were used for domain imaging and polarization switching studies. To verify the piezoresponse, we applied a $10 \mathrm{~V}$ AC driving voltage on the sample to measure the normal and shear responses, with the AC frequency set at the second resonant peak of cantileversample system (340 kHz for normal response and $720 \mathrm{kHz}$ for shear response) to enhance the sensitivity. The measurement was carried out on the thin grains, which were prepared as follows. Firstly, commercial ITO-coated glass substrate was sequentially ultrasonic cleaned in ethanol for 20 minutes. A drop of aqueous solution of $(\mathrm{R} 3 \mathrm{HQ})_{4} \mathrm{RbCe}\left(\mathrm{NO}_{3}\right)_{8}(20 \mathrm{mg} / \mathrm{mL})$ was carefully spread on a freshly cleaned ITO-coated glass. The slow evaporation gave the thin film consisting of small thin grains. The film was heated at $330 \mathrm{~K}$ for a few hours and then cooled slowly so that the solvent was 
removed completely and the domain structure can be formed.
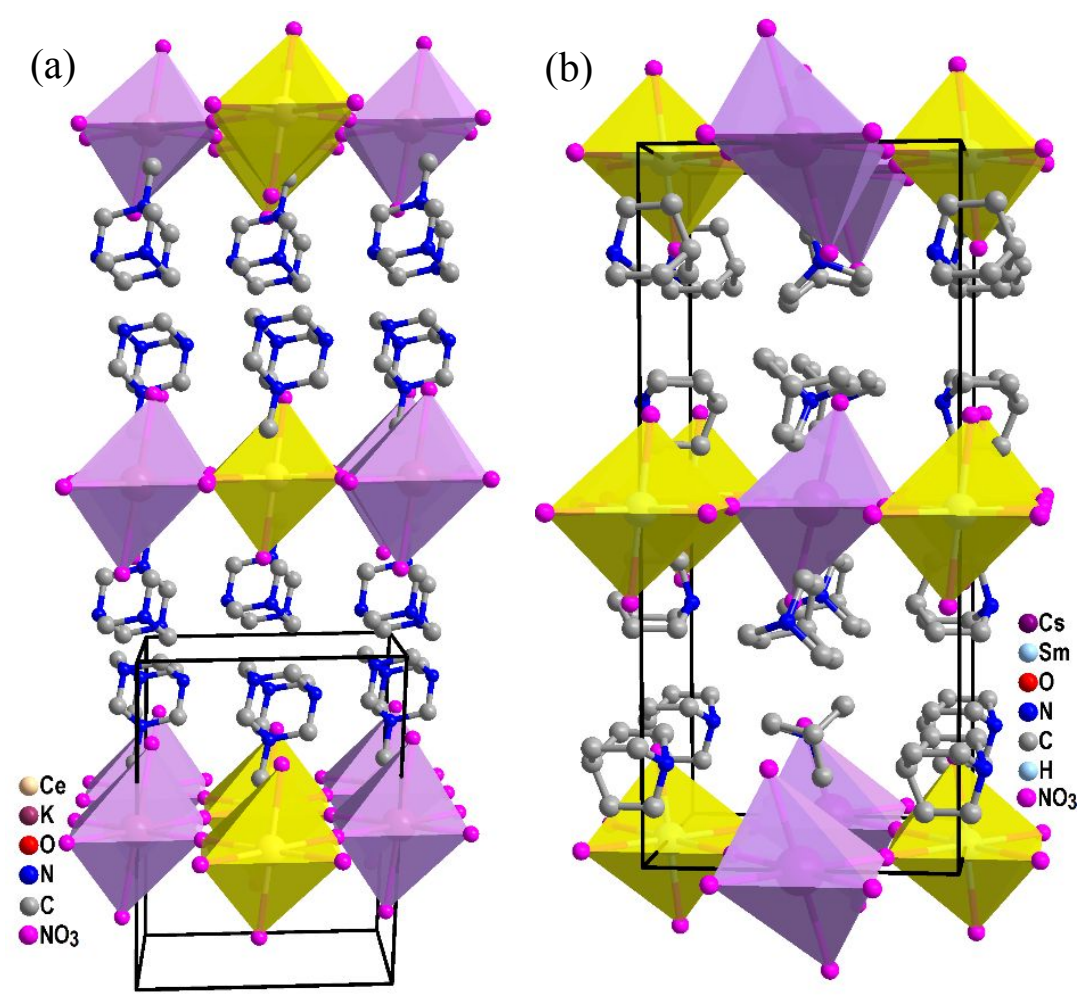

Figure S1. The 2D layered rare-earth double perovskite structures of (a) $(\mathrm{MU})_{4} \mathrm{KCe}\left(\mathrm{NO}_{3}\right)_{8}$ and (b) $\mathrm{Q}_{4} \mathrm{CsSm}\left(\mathrm{NO}_{3}\right)_{8}$. The $\mathrm{NO}_{3}{ }^{-}$ions are indicated with the pink balls for clarity.
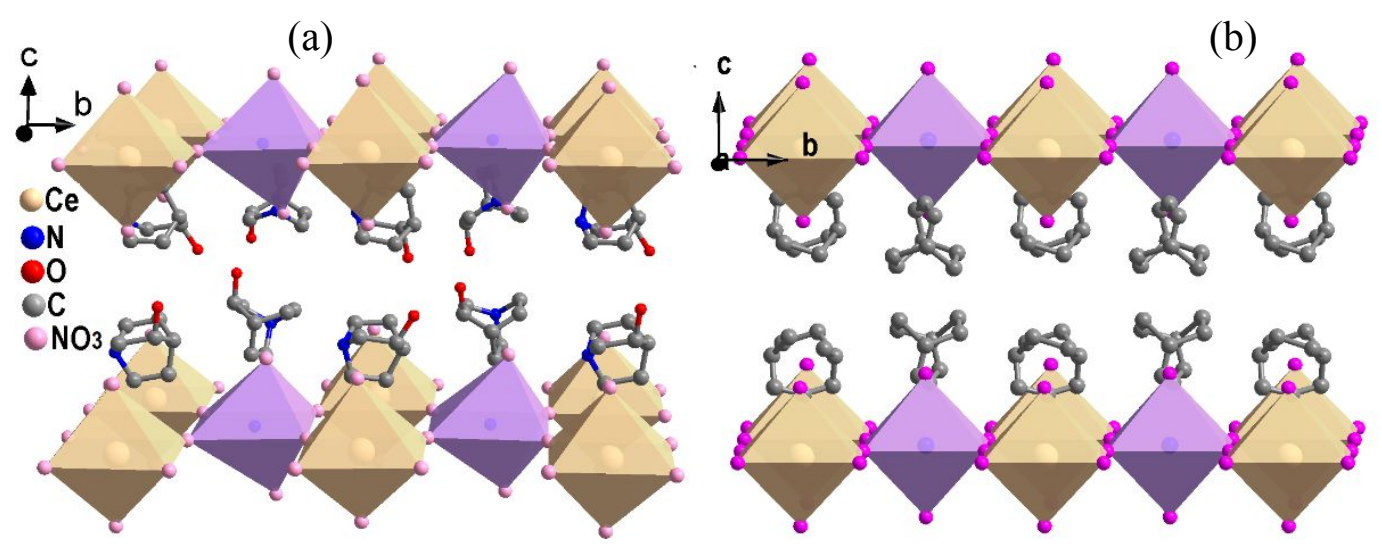

Figure S2. The (a) ferroelectric and (b) paraelectric structures of (R3HQ) ${ }_{4} \mathrm{NH}_{4} \mathrm{Ce}\left(\mathrm{NO}_{3}\right)_{8}$. $\mathrm{The} \mathrm{NO}_{3}{ }^{-}$ ions are also disordered in the paraelectric phase, but not shown. The ferroelectric and paraelectric phases of $(\mathrm{R} 3 \mathrm{HQ})_{4} \mathrm{RbTb}\left(\mathrm{NO}_{3}\right)_{8}$ and $(\mathrm{R} 3 \mathrm{HQ})_{4} \mathrm{RbDy}\left(\mathrm{NO}_{3}\right)_{8}$ were refined with the same models as those for $(\mathrm{R} 3 \mathrm{HQ})_{4} \mathrm{NH}_{4} \mathrm{Ce}\left(\mathrm{NO}_{3}\right)_{8}$, respectively. 

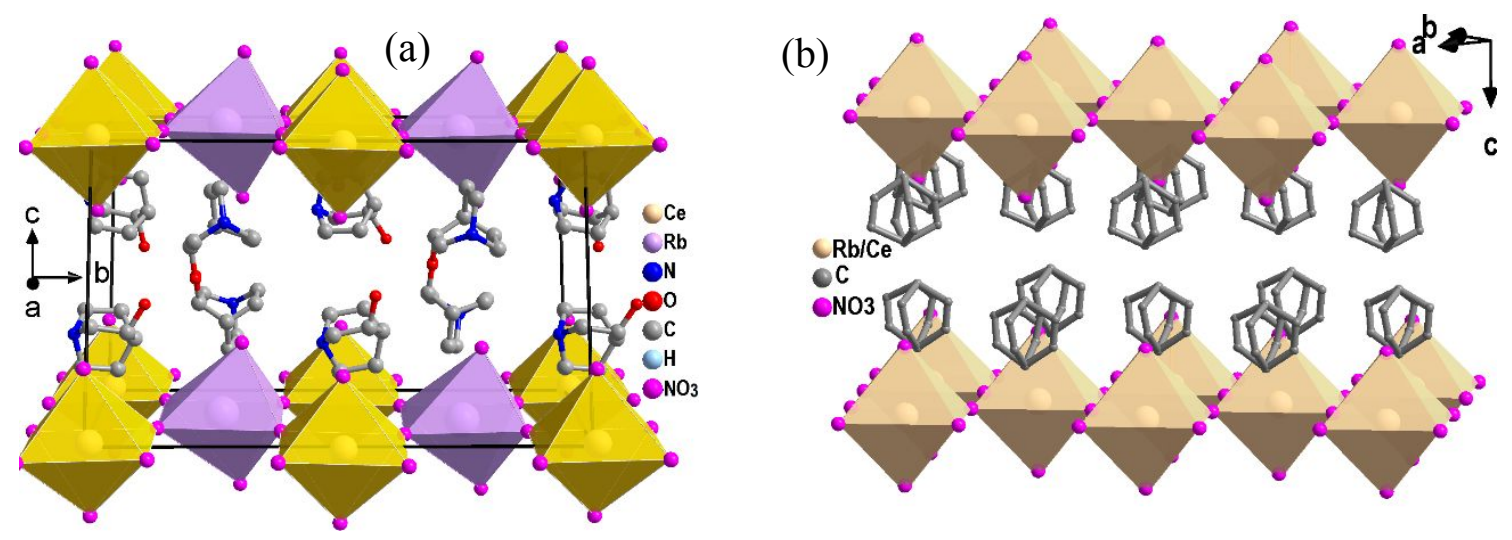

Figure S3. The (a) ferroelectric and (b) paraelectric structures of $(\mathrm{R} 3 \mathrm{HQ})_{4} \mathrm{RbCe}\left(\mathrm{NO}_{3}\right)_{8}$. The paraelectric phase shows the pseudo tetragonal symmetry. The ferroelectric and paraelectric phases of $(\mathrm{R} 3 \mathrm{HQ})_{4} \mathrm{RbEu}\left(\mathrm{NO}_{3}\right)_{8}$ and $(\mathrm{R} 3 \mathrm{HQ})_{4} \mathrm{RbSm}\left(\mathrm{NO}_{3}\right)_{8}$ were refined with the same models, respectively.
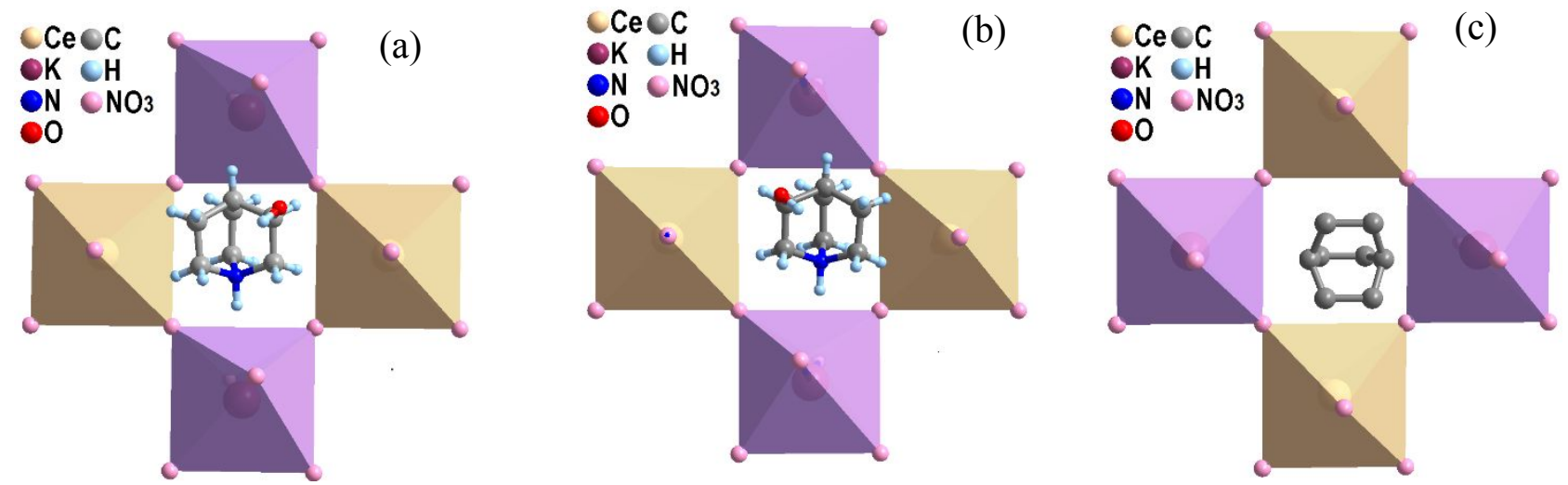

Figure S4. The structural similarity of layered (a) $(\mathrm{R} 3 \mathrm{HQ})_{4} \mathrm{KCe}\left(\mathrm{NO}_{3}\right)_{8}$, (b) $(\mathrm{S} 3 \mathrm{HQ})_{4} \mathrm{KCe}\left(\mathrm{NO}_{3}\right)_{8}$ and (c) $(\mathrm{Rac} 3 \mathrm{HQ})_{4} \mathrm{KCe}\left(\mathrm{NO}_{3}\right)_{8}$. The highly disordered Rac3HQ cation in $(\mathrm{Rac} 3 \mathrm{HQ})_{4} \mathrm{KCe}\left(\mathrm{NO}_{3}\right)_{8}$ was modeled as a ball-like molecule with no chemical sense.
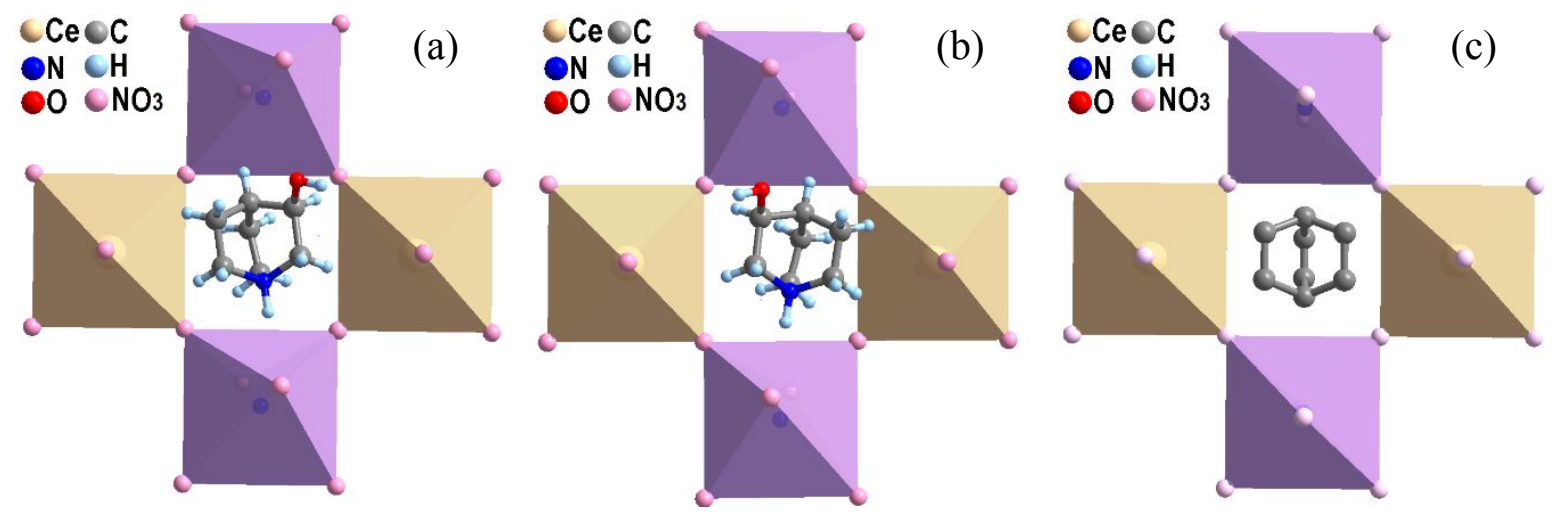

Figure S5. The structural similarity of layered (a) $(\mathrm{R} 3 \mathrm{HQ})_{4} \mathrm{NH}_{4} \mathrm{Ce}\left(\mathrm{NO}_{3}\right)_{8}$, (b) $(\mathrm{S} 3 \mathrm{HQ})_{4} \mathrm{NH}_{4} \mathrm{Ce}\left(\mathrm{NO}_{3}\right)_{8}$ and (c) (Rac3HQ) $)_{4} \mathrm{NH}_{4} \mathrm{Ce}\left(\mathrm{NO}_{3}\right)_{8}$. The highly disordered Rac3HQ cation in (Rac3HQ) ${ }_{4} \mathrm{NH}_{4} \mathrm{Ce}\left(\mathrm{NO}_{3}\right)_{8}$ was modeled as a ball-like molecule with no chemical sense. 


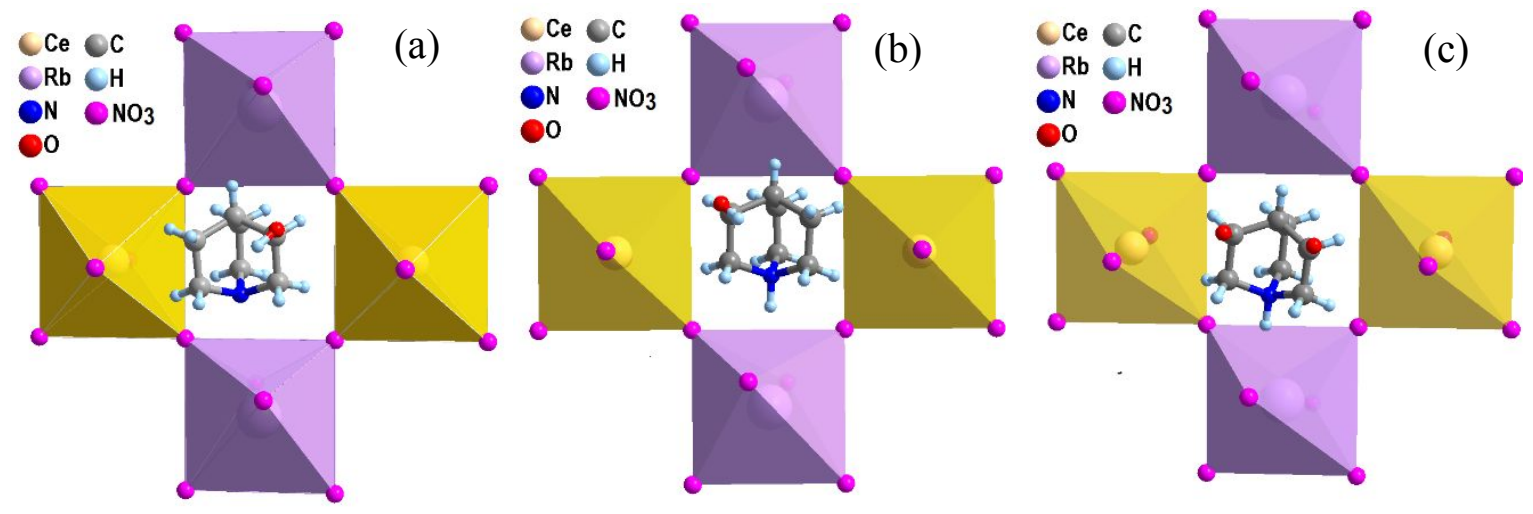

Figure S6. The structural similarity of layered (a) (R3HQ) $)_{4} \mathrm{RbCe}\left(\mathrm{NO}_{3}\right)_{8}$, (b) $(\mathrm{S} 3 \mathrm{HQ})_{4} \mathrm{RbCe}\left(\mathrm{NO}_{3}\right)_{8}$ and (c) $(\mathrm{Rac} 3 \mathrm{HQ})_{4} \mathrm{RbCe}\left(\mathrm{NO}_{3}\right)_{8}$.
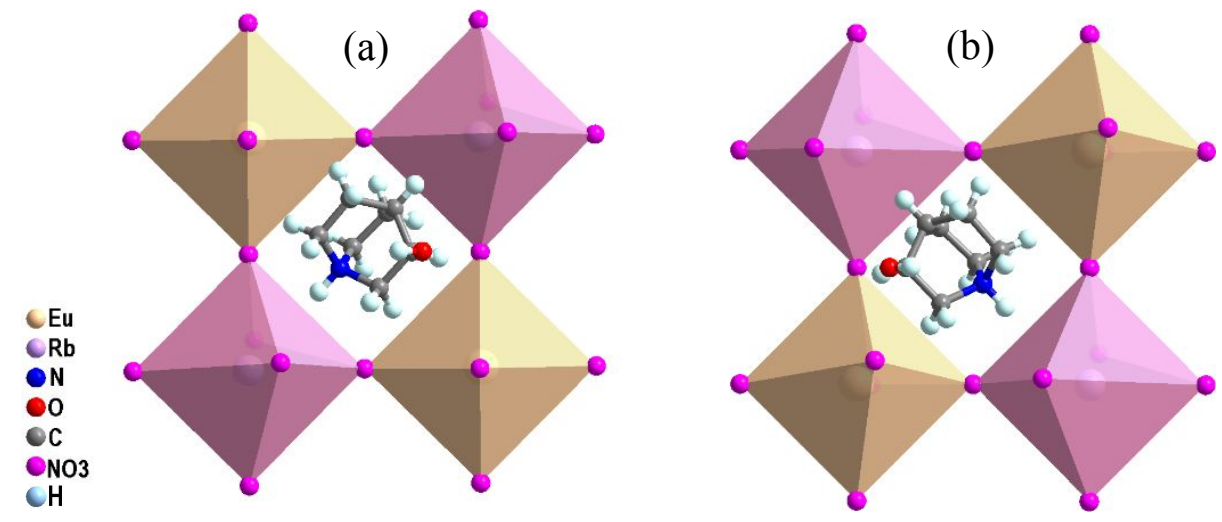

Figure S7. Ferroelectric enantiomers of (R3HQ) $)_{4} \mathrm{RbEu}\left(\mathrm{NO}_{3}\right)_{8}$ and $(\mathrm{S} 3 \mathrm{HQ})_{4} \mathrm{RbEu}\left(\mathrm{NO}_{3}\right)_{8}$.

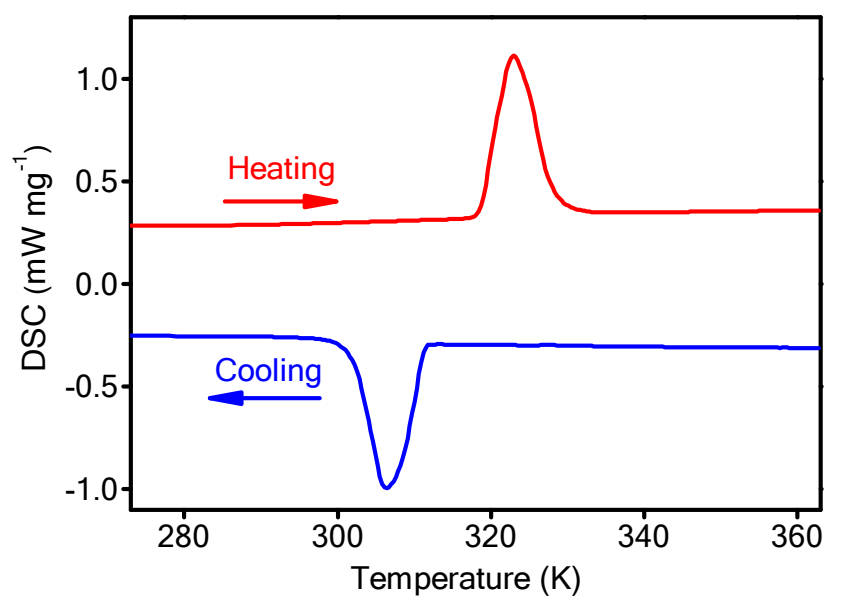

Figure S8. DSC curve for $(\mathrm{S} 3 \mathrm{HQ})_{4} \mathrm{KCe}\left(\mathrm{NO}_{3}\right)_{8}$ in a heating-cooling cycle. 

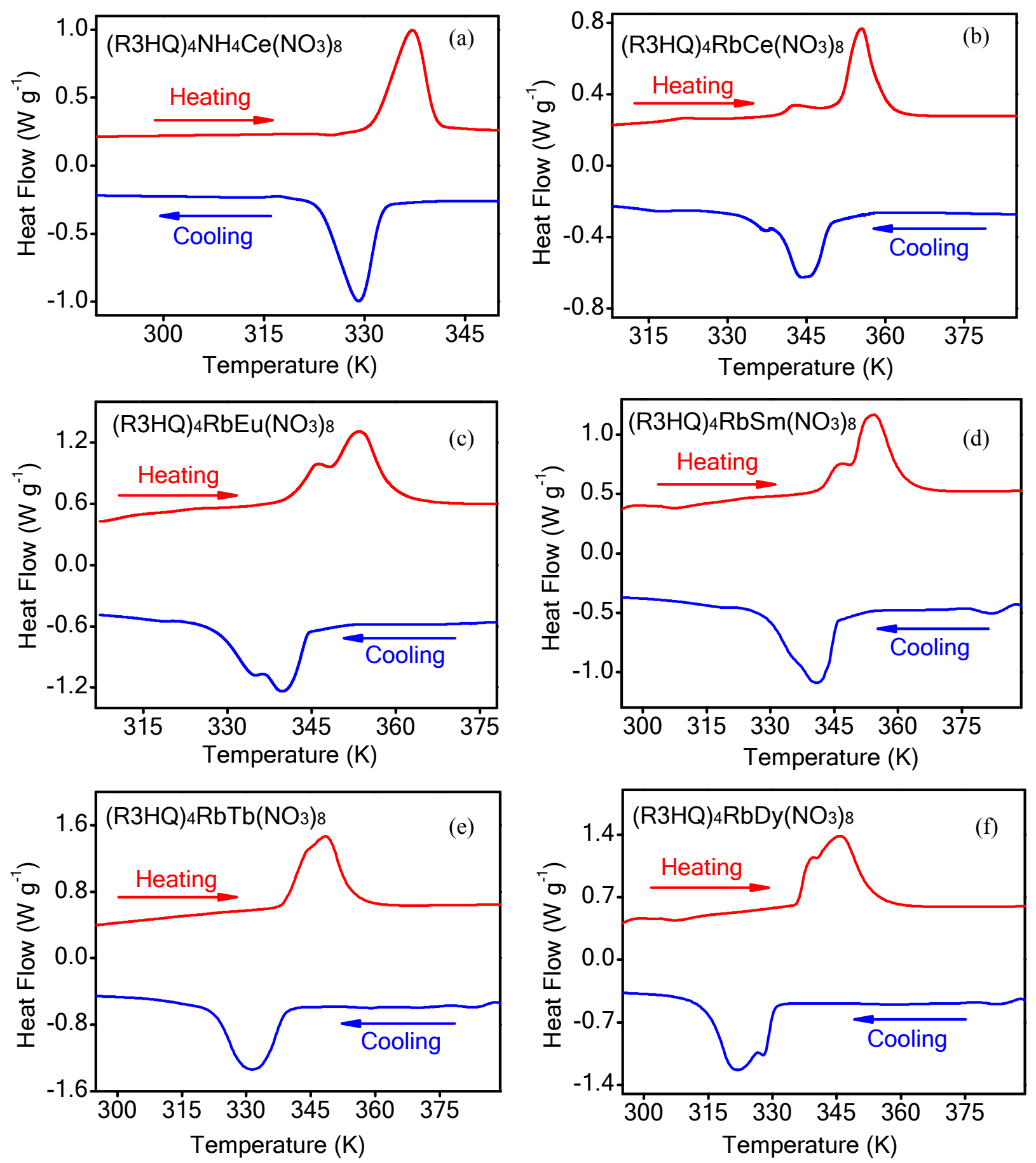

Figure S9. DSC curves for the isostructural ferroelectrics, (R3HQ) $)_{4} \mathrm{NH}_{4} \mathrm{Ce}\left(\mathrm{NO}_{3}\right)_{8}\left(T_{\mathrm{c}}=\sim 333 \mathrm{~K}\right)$, $(\mathrm{R} 3 \mathrm{HQ})_{4} \mathrm{RbCe}\left(\mathrm{NO}_{3}\right)_{8}\left(T_{\mathrm{c}}=\sim 350 \mathrm{~K}\right),(\mathrm{R} 3 \mathrm{HQ})_{4} \mathrm{RbEu}\left(\mathrm{NO}_{3}\right)_{8}\left(T_{\mathrm{c}}=\sim 347 \mathrm{~K}\right),(\mathrm{R} 3 \mathrm{HQ})_{4} \mathrm{RbSm}\left(\mathrm{NO}_{3}\right)_{8}\left(T_{\mathrm{c}}\right.$ $=\sim 350 \mathrm{~K}),(\mathrm{R} 3 \mathrm{HQ})_{4} \mathrm{RbTb}\left(\mathrm{NO}_{3}\right)_{8}\left(T_{\mathrm{c}}=\sim 340 \mathrm{~K}\right)$ and $(\mathrm{R} 3 \mathrm{HQ})_{4} \mathrm{RbDy}\left(\mathrm{NO}_{3}\right)_{8}\left(T_{\mathrm{c}}=\sim 333 \mathrm{~K}\right)$. The composite peaks in (b)-(f) indicate the complex dynamical processes during the phase transitions, since the both the nitrate ions and organic cations become totally disordered in the high temperature 
phases.

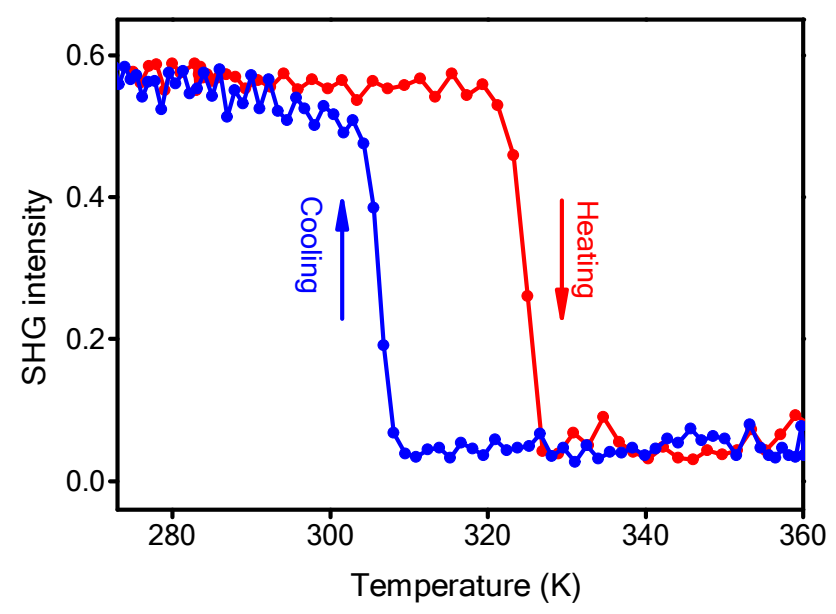

Figure S10. Temperature dependence of the SHG intensity (relative to that of KDP) for $(\mathrm{S} 3 \mathrm{HQ})_{4} \mathrm{KCe}\left(\mathrm{NO}_{3}\right)_{8}$ in a heating-cooling cycle.
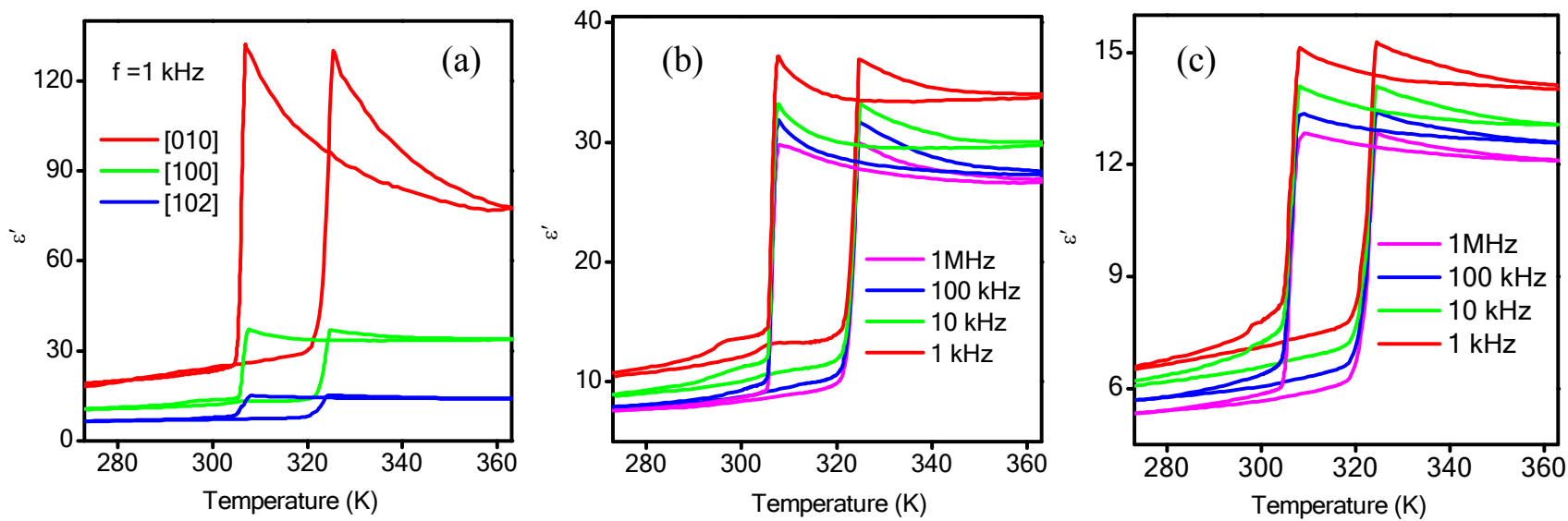

Figure S11. Dielectric anisotropy of $(\mathrm{R} 3 \mathrm{HQ})_{4} \mathrm{KCe}\left(\mathrm{NO}_{3}\right)_{8}$. (a) Comparison of the dielectric responses along different direction in a heating-cooling cycle. (b) The dielectric responses along the $a$-direction. (c) The dielectric responses along [102]-direction.
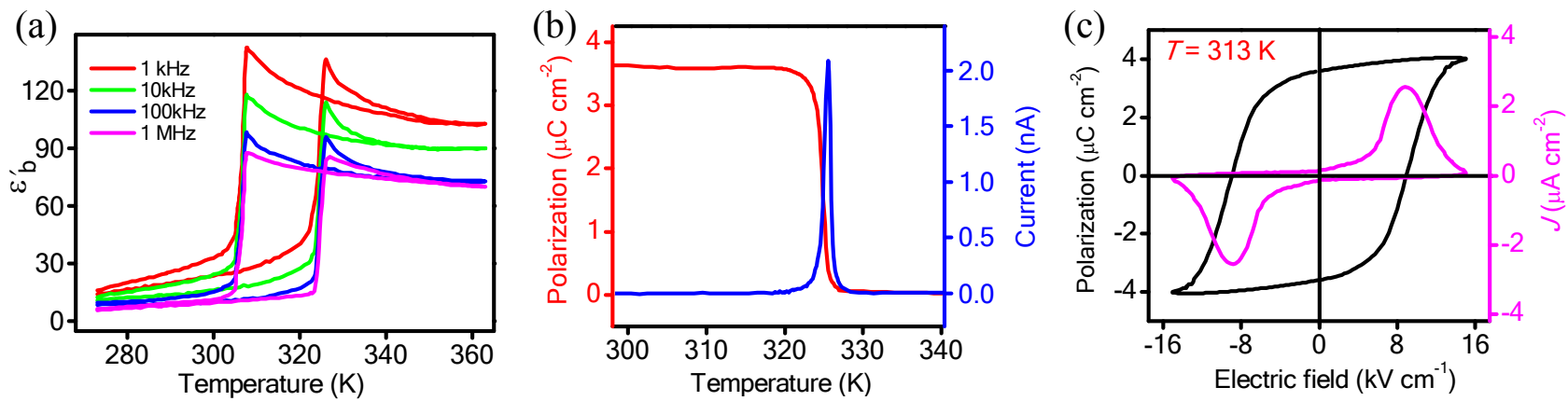

Figure S12. Ferroelectricity and related properties of $(\mathrm{S} 3 \mathrm{HQ})_{4} \mathrm{KCe}\left(\mathrm{NO}_{3}\right)_{8}$. (a) Dielectric curves in a heating-cooling cycle. (b) Pyroelectric current curve in a heating run and the temperature dependence 
of the determined $P_{\mathrm{s}}$. (c) $J-E$ (current density-electric field) curve and ferroelectric hysteresis loop at $313 \mathrm{~K}$. These properties are measured along the $b$-axis.

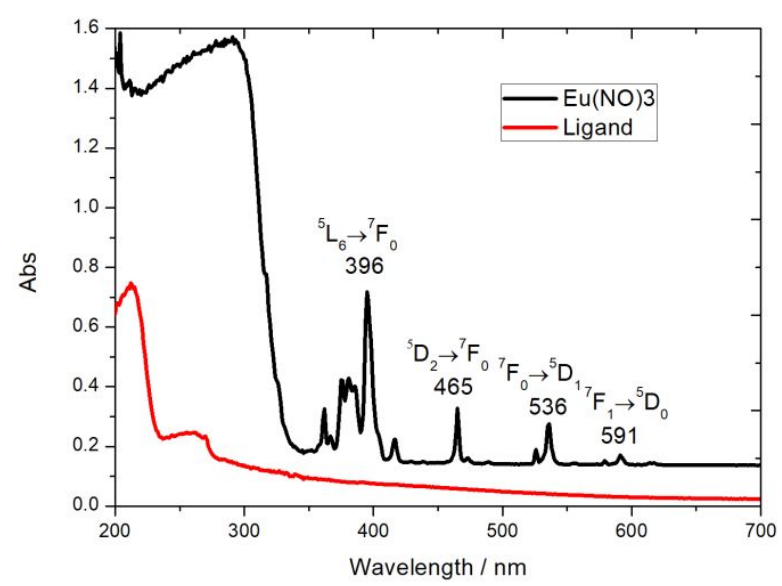

Figure S13. Absorption spectra of the starting materials $\mathrm{Eu}\left(\mathrm{NO}_{3}\right)_{3} \cdot 6 \mathrm{H}_{2} \mathrm{O}$ and 3-quinuclidinol.
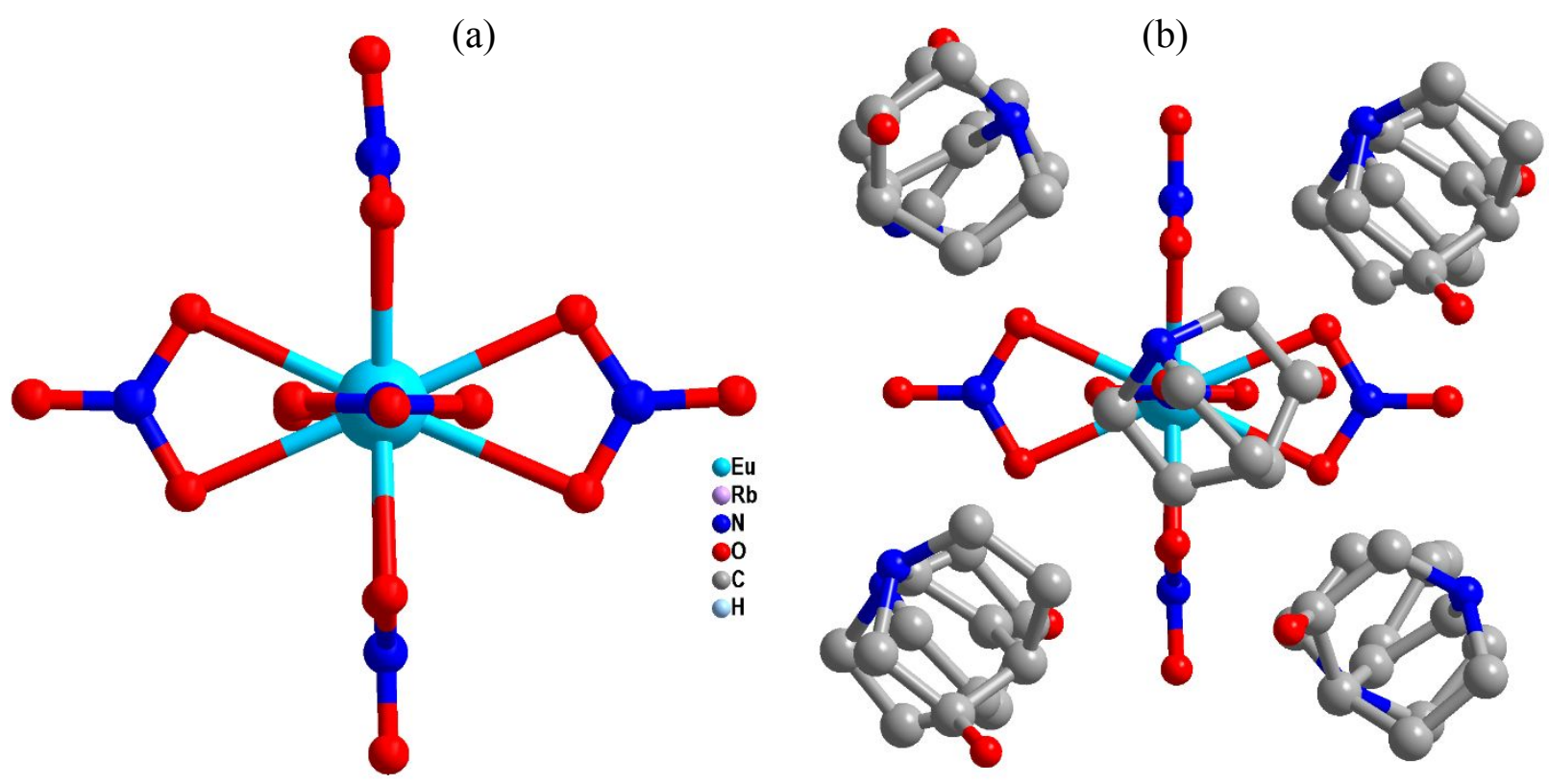

Figure S14. Local symmetry of the $\mathrm{Eu}^{3+}$ ion in $(\mathrm{R} 3 \mathrm{HQ})_{4} \mathrm{RbEu}\left(\mathrm{NO}_{3}\right)_{8}$. (a) The structure of the $\mathrm{Eu}\left(\mathrm{NO}_{3}\right)_{6}$, showing the pseudo $\mathrm{mmm}$ symmetry. (b) Projection of the crystal structure of (R3HQ) ${ }_{4} \mathrm{RbEu}\left(\mathrm{NO}_{3}\right)_{8}$ along the pseudo fourfold axis. $\mathrm{Rb}$ ions and $\mathrm{H}$ atoms were omitted for clarity. 

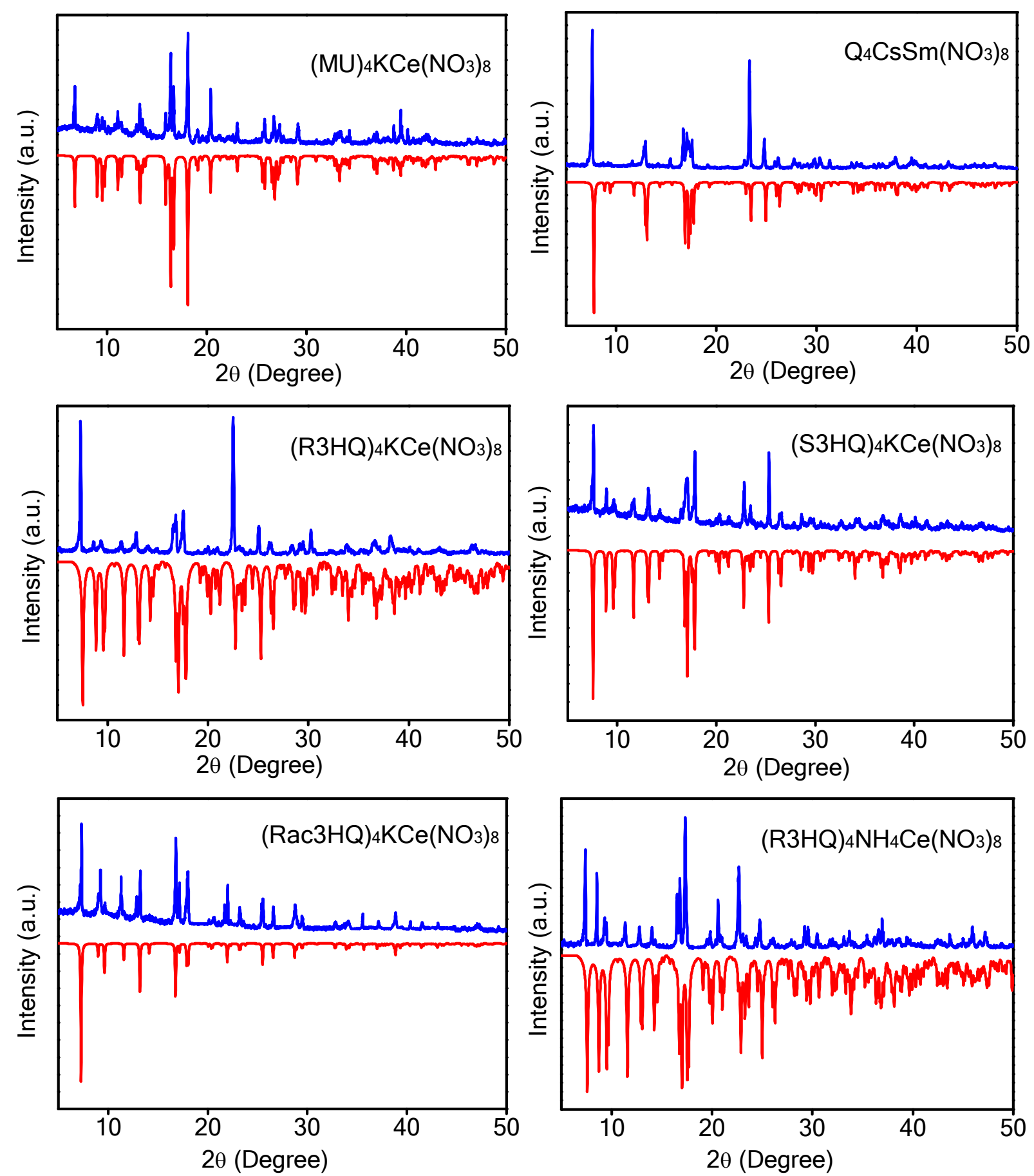

Figure S15. Patterns of the powder X-ray diffraction for $(\mathrm{MU})_{4} \mathrm{KCe}\left(\mathrm{NO}_{3}\right)_{8}, \mathrm{Q}_{4} \mathrm{CsSm}\left(\mathrm{NO}_{3}\right)_{8}$, $(\mathrm{R} 3 \mathrm{HQ})_{4} \mathrm{KCe}\left(\mathrm{NO}_{3}\right)_{8},(\mathrm{~S} 3 \mathrm{HQ})_{4} \mathrm{KCe}\left(\mathrm{NO}_{3}\right)_{8},(\mathrm{Rac} 3 \mathrm{HQ})_{4} \mathrm{KCe}\left(\mathrm{NO}_{3}\right)_{8},(\mathrm{R} 3 \mathrm{HQ})_{4} \mathrm{NH}_{4} \mathrm{Ce}\left(\mathrm{NO}_{3}\right)_{8}$. For each panel, the red curve is that simulated from the single-crystal structure, while the blue cure is the experimental result. 

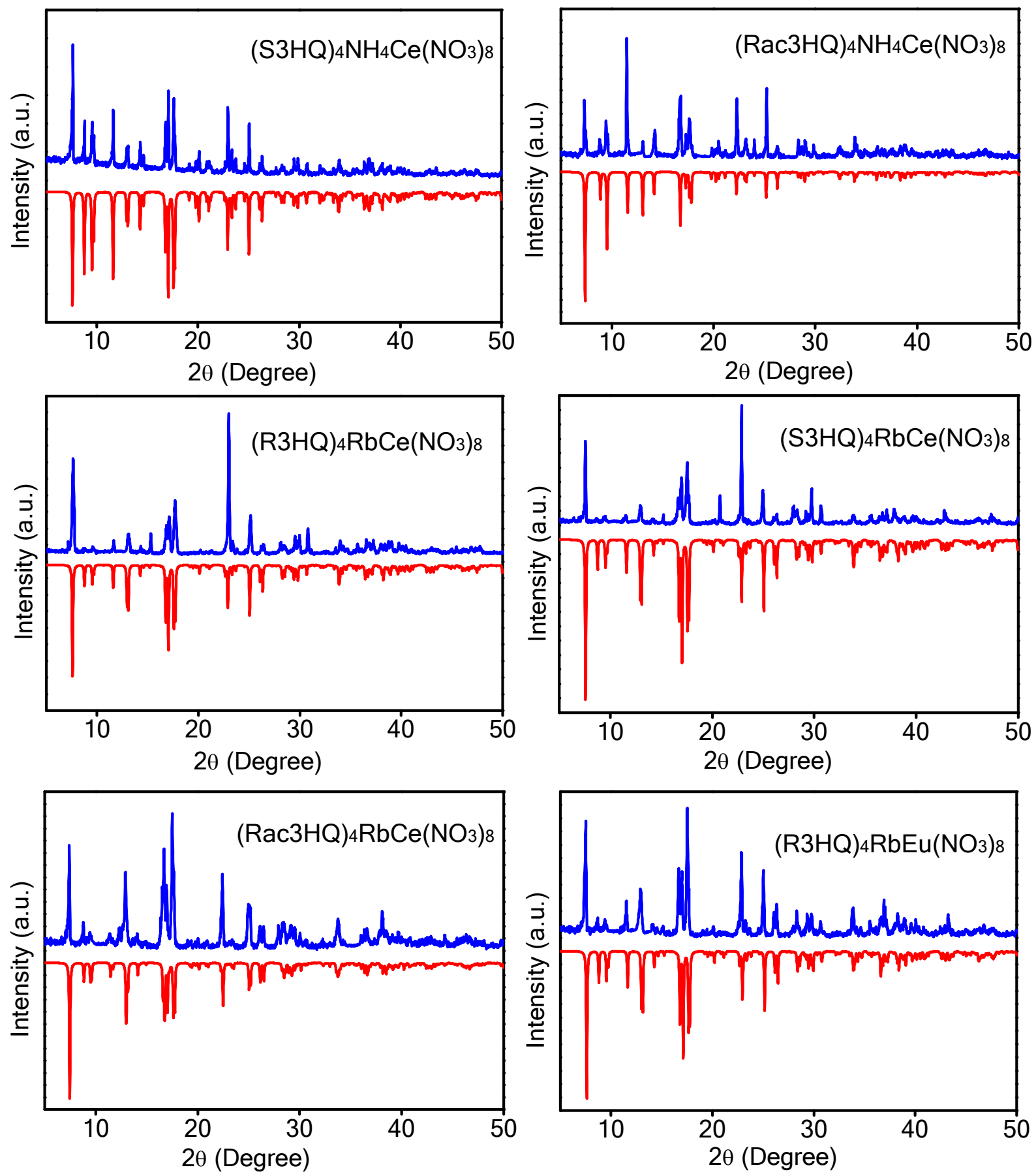

Figure S16. Patterns of the powder X-ray diffraction for $(\mathrm{S} 3 \mathrm{HQ})_{4} \mathrm{NH}_{4} \mathrm{Ce}\left(\mathrm{NO}_{3}\right)_{8}$, $(\mathrm{Rac} 3 \mathrm{HQ})_{4} \mathrm{NH}_{4} \mathrm{Ce}\left(\mathrm{NO}_{3}\right)_{8}, \quad(\mathrm{R} 3 \mathrm{HQ})_{4} \mathrm{RbCe}\left(\mathrm{NO}_{3}\right)_{8}, \quad(\mathrm{~S} 3 \mathrm{HQ})_{4} \mathrm{RbCe}\left(\mathrm{NO}_{3}\right)_{8}, \quad(\mathrm{Rac} 3 \mathrm{HQ})_{4} \mathrm{RbCe}\left(\mathrm{NO}_{3}\right)_{8}$, $(\mathrm{R} 3 \mathrm{HQ})_{4} \mathrm{RbEu}\left(\mathrm{NO}_{3}\right)_{8}$. 

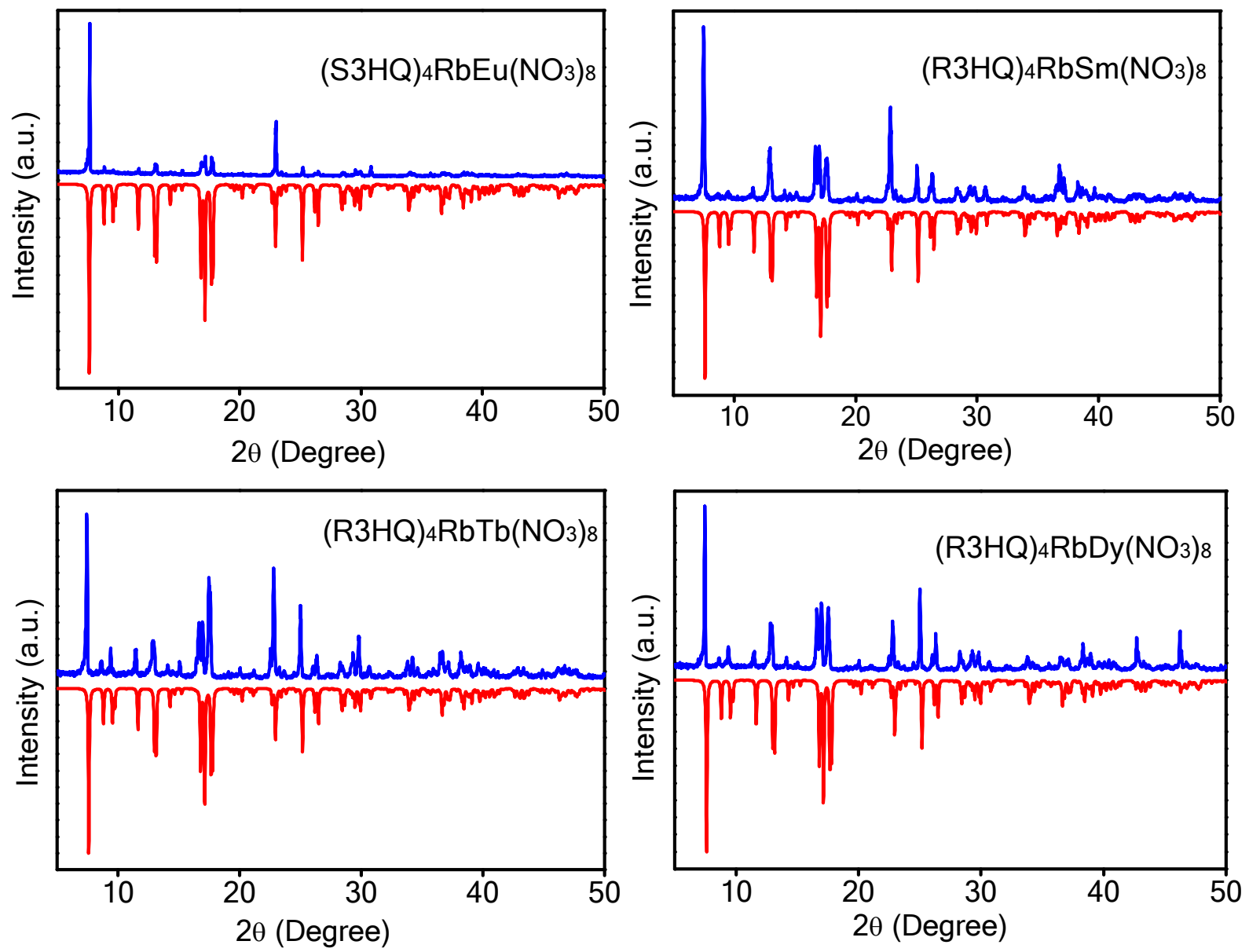

Figure S17. Patterns of the powder X-ray diffraction for $\left.(\mathrm{S} 3 \mathrm{HQ})_{4} \mathrm{RbEu}\left(\mathrm{NO}_{3}\right)_{8},(\mathrm{R} 3 \mathrm{HQ})_{4} \mathrm{RbSm}_{(\mathrm{NO}}\right)_{8}$, $(\mathrm{R} 3 \mathrm{HQ})_{4} \mathrm{RbTb}\left(\mathrm{NO}_{3}\right)_{8},(\mathrm{R} 3 \mathrm{HQ})_{4} \mathrm{RbDy}\left(\mathrm{NO}_{3}\right)_{8}$.
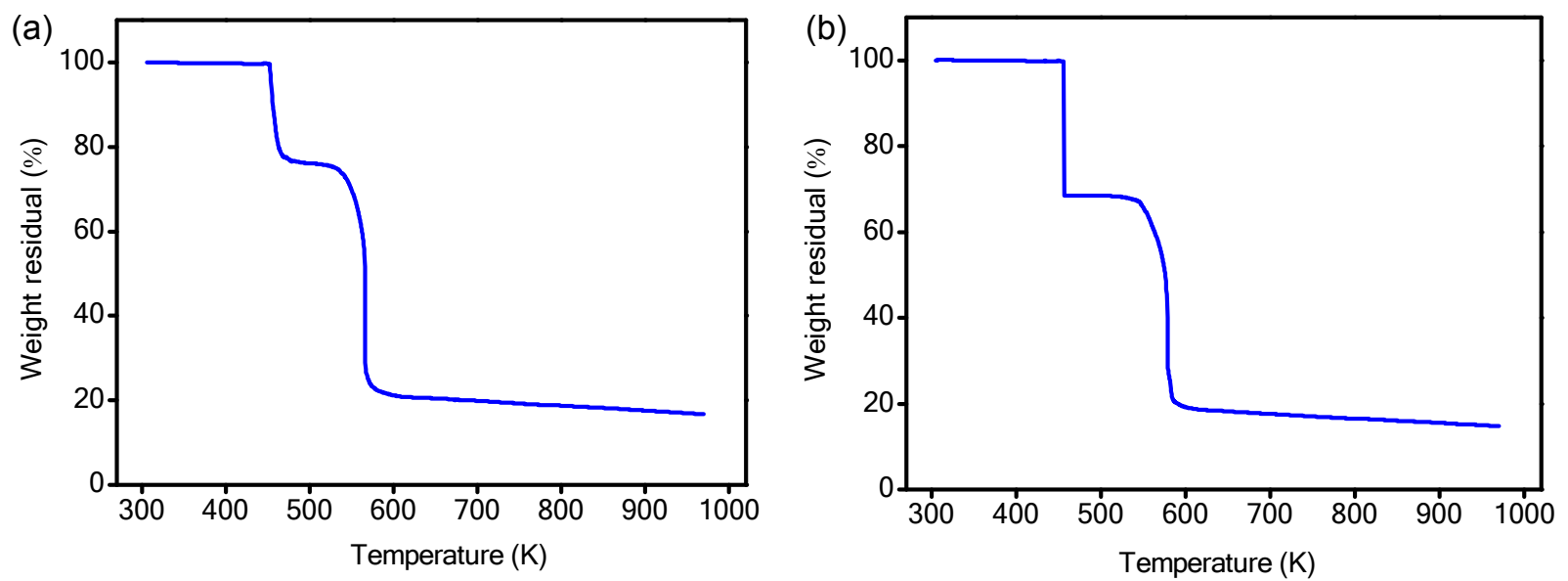

Figure S18. The TGA curve for (a) (R3HQ) $)_{4} \mathrm{KCe}\left(\mathrm{NO}_{3}\right)_{8}$ and (b) $(\mathrm{S} 3 \mathrm{HQ})_{4} \mathrm{KCe}\left(\mathrm{NO}_{3}\right)_{8}$, reveals thermal stability up to $450 \mathrm{~K}$, far higher than $T_{\mathrm{c}}$. 


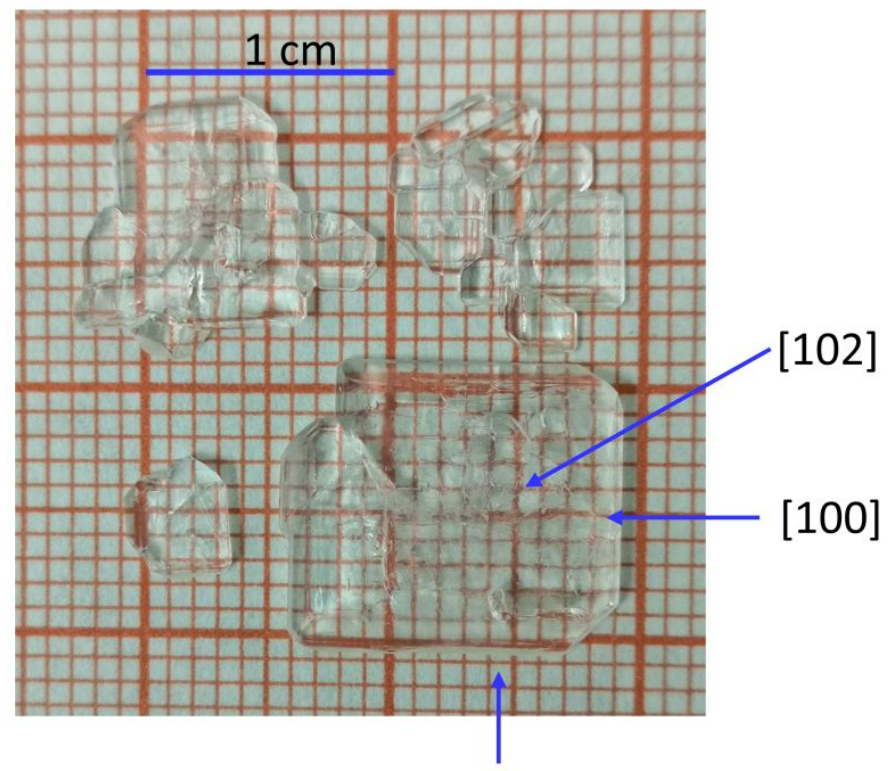

[010]

Figure S19. A picture of large crystals of $(\mathrm{R} 3 \mathrm{HQ})_{4} \mathrm{KCe}\left(\mathrm{NO}_{3}\right)_{8}$. The crystals have the similar shape. Three directions of the large crystal are indicated. The [102]-direction, which perpendicular to the largest face, is perpendicular to the inorganic layers, the [010]-direction is along the polar axis and parallel to the inorganic layers, and [100]-direction is perpendicular to the polar axis and parallel to the inorganic layers. 


\section{Evaluation of $P_{\mathrm{s}}$ for $(\mathrm{R} 3 \mathrm{HQ})_{4} \mathrm{KCe}\left(\mathrm{NO}_{3}\right)_{8}$ with the point charge model}

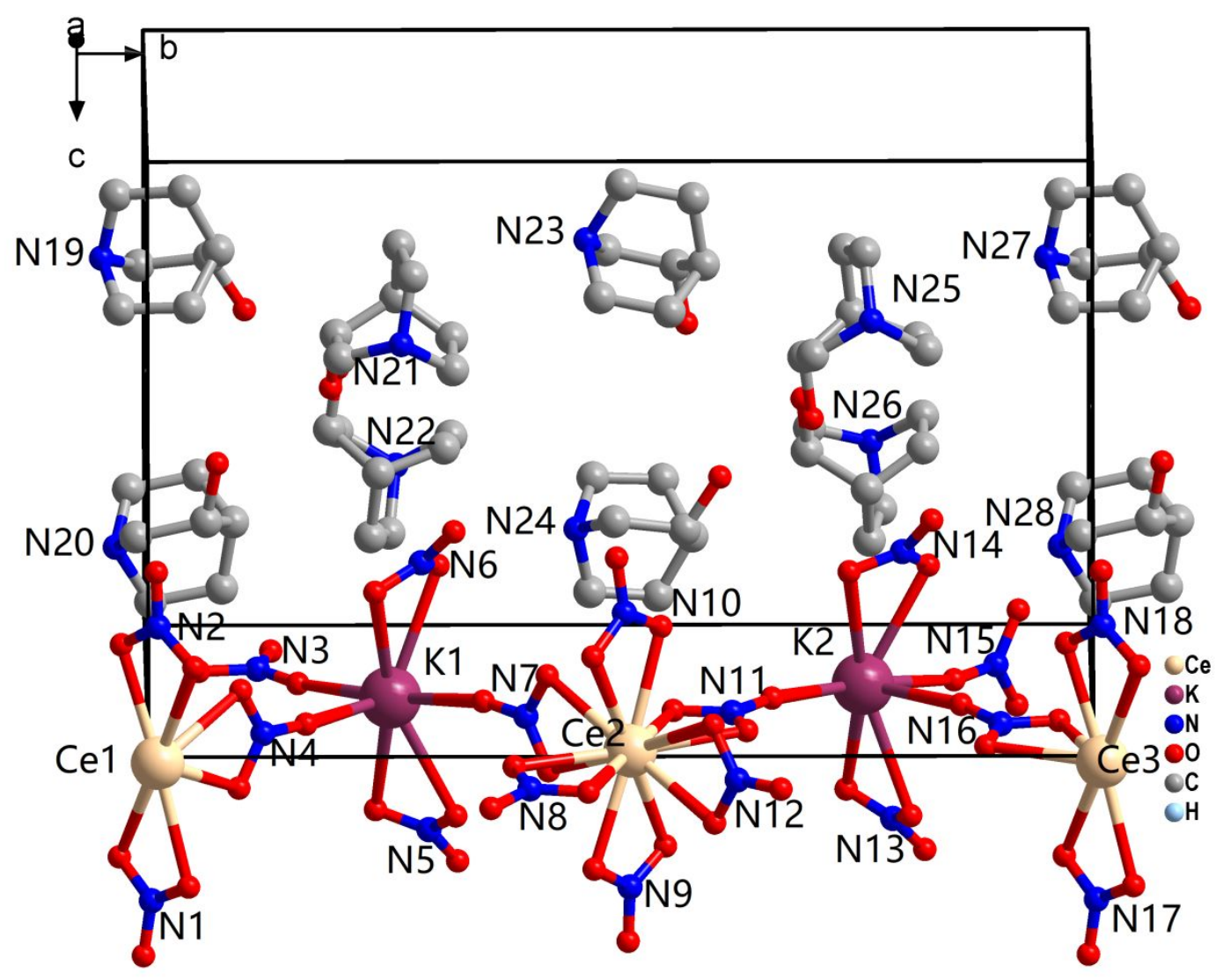

Figure S20. A unit cell of (R3HQ) $)_{4} \mathrm{KCe}\left(\mathrm{NO}_{3}\right)_{8}$. The $\mathrm{N}_{\text {nitrate }}, \mathrm{N}_{\mathrm{R} 3 \mathrm{HQ}}, \mathrm{K}^{+}$and $\mathrm{Ce}^{3+}$ are numbered.

The point charge model was used to evaluate $P_{\mathrm{s}}$ by assuming that the negative charges are located on the $\mathrm{N}_{\text {nitrate }}$ atoms, while the positive charges are located on the $\mathrm{N}_{\mathrm{R} 3 \mathrm{HQ}}$ atoms, $\mathrm{K}^{+}$and $\mathrm{Ce}^{3+}$ ions. One unit was chosen for the calculation. As shown in Figure S20, the selected unit cell contains five pairs of translation-related ions, including Ce1 and Ce3, N1 and N17, N2 and N18, N19 and N27, and N20 and N28. The charge contribution of each of the ten ions to the selected unit cell is half of its charge. For example, Ce1 contributes $1.5 \mathrm{e}$ to the unit cell, while $\mathrm{N} 1$ contributes $-0.5 \mathrm{e}$ to the unit cell. Accordingly, a unit cell have positive and negative charges of $16 \mathrm{e}$, respectively. The charge distribution within the selected unit cell is listed in Table S1. 
Table S1. Charge distribution in (R3HQ) ${ }_{4} \mathrm{KCe}\left(\mathrm{NO}_{3}\right)_{8}$. Only $b$-axis-fractional coordinates of the charge carriers are shown.

\begin{tabular}{|llll|}
\hline $\mathrm{N}^{-}$nitrate & & \\
\hline $\mathrm{N} 1(0.0034(3))$ & $\mathrm{N} 2(0.0098(3))$ & $\mathrm{N} 3(0.1186(2))$ & $\mathrm{N} 4(0.1221(2))$ \\
$\mathrm{N} 5(0.2995(2))$ & $\mathrm{N} 6(0.2902(2))$ & $\mathrm{N} 7(0.4003(2))$ & $\mathrm{N} 8(0.4027(2))$ \\
$\mathrm{N} 9(0.5098(3))$ & $\mathrm{N} 10(0.5034(3))$ & $\mathrm{N} 11(0.6186(2))$ & $\mathrm{N} 12(0.6221(2))$ \\
$\mathrm{N} 13(0.7902(2))$ & $\mathrm{N} 14(0.7995(2))$ & $\mathrm{N} 15(0.9003(2))$ & $\mathrm{N} 16(0.9027(2))$ \\
$\mathrm{N} 17(1.0034(3))$ & $\mathrm{N} 18(1.0098(3))$ & \\
\hline $\mathrm{Ce}^{3+}$ & & \\
\hline $\mathrm{Ce} 1(0.0098(0))$ & $\mathrm{Ce} 2(0.5098(0))$ & $\mathrm{Ce} 3(1.0098(0))$ & \\
\hline $\mathrm{K}^{+}$ & & \\
\hline $\mathrm{K} 1(0.2581(1))$ & $\mathrm{K} 2(0.7581(1))$ & $\mathrm{N} 22(0.2664(2))$ \\
\hline $\mathrm{N}^{+}$R3HQ & & \\
\hline $\mathrm{N} 19(-0.0455(2))$ & $\mathrm{N} 20(-0.0329(2))$ & $\mathrm{N} 21(0.2687(3))$ \\
$\mathrm{N} 23(0.4670(2))$ & $\mathrm{N} 24(0.4544(2))$ & $\mathrm{N} 25(0.7664(2))$ & \\
$\mathrm{N} 27(0.9544(2))$ & $\mathrm{N} 28(0.9670(2))$ & \\
\hline \multicolumn{4}{l}{ The center of the positive charges } \\
\hline
\end{tabular}

$P_{\mathrm{s}}=\lim \frac{1}{V} \sum q_{i} r_{i}$

$=[(16 \times \mathrm{e}) \times(0.4999 \times b)+(-16 \times \mathrm{e}) \times(0.5183 \times b)] / V$,

where $\mathrm{e}=1.6 \times 10^{-19} \mathrm{C}, b=19.9635 \times 10^{-10} \mathrm{~m}$ and $V=2327.84 \times 10^{-30} \mathrm{~m}^{3}$.

$\left|P_{\mathrm{s}}\right| \approx 0.04 \mathrm{C} \mathrm{m}^{-2}=4 \mu \mathrm{C} \mathrm{cm}^{-2}$ 